\title{
Attacks on adult females with infants by non-resident males in the François langur
}

\author{
Qi-Hai ZHOU, Bang LUO, Cheng-Ming HUANG*
}

College of Life Science, Guangxi Normal University, Guilin 541004, China

\begin{abstract}
Infanticide by males is a common phenomenon in mammals, especially primates, as lactation lasts much longer than gestation in many species. Usually, infanticidal episodes occur soon after group takeovers, and are traditionally considered a male reproductive strategy (i.e., support the sexual selection hypothesis, Hrdy, 1974). To verify the validity of this conception, we observed one group of François' langurs in the Nonggang Nature Reserve, China, between August 2003 and July 2004. During the study period, a François' langur female with the youngest infant in the group was attacked three times by immigrating males, and later disappeared by the third day after the final attack. We suggest that these attacks on the female-infant dyad represent infanticide attempts by males, and may be the cause of the adult female and her infant's disappearance. Presumably, that female dispersed with her infant to avoid infanticide and was not killed. Though these observations do not completely verify the sexual selection hypothesis, they are not inconsistent with it.
\end{abstract}

Keywords: Infanticide; Reproductive tactics; François' langur (Trachypithecus francoisi)

Infanticide by males is a common phenomenon among some mammal taxa. In primates, this occurs because some species show a period of lactation longer than gestation (van Schaik \& Janson, 2000). Researchers have proposed numerous hypotheses to explain the significance of infanticide, such as the sexual selection (Hrdy, 1979; van Schaik \& Janson, 2000), resource competition (Agoramoorthy \& Rudran, 1995), and social pathology hypotheses (Boggess, 1979). Among male infanticide in primates, sex selection is usually supported by observational data (Hrdy, 1979; van Schaik \& Janson, 2000), even though this hypothesis is still occasionally debated in authropological circles (Sussman et al, 1995; Sommer, 2000). Based on the sexual selection hypothesis, infanticide is thought to be male reproductive strategy whereby males prevent females from investing in offspring sired by other males, thus increasing the chance of siring offspring of their own (Hrdy, 1979, van Schaik \& Janson, 2000).

Because detecting infanticide is difficult, many reports of infanticide in primates have been based on indirect observations (Newton \& Dunbar, 1994; Steenbeek, 2000). To more directly examine if the sexual selection hypothesis bears out in certain primates, we began observing a group of François' langurs. The François' langur (Trachypithecus francoisi) is an endangered colobine species, ranging from the Red River in northern Vietnam to Guangxi, Guizhou, and Chongqing in southern China (Groves, 2001; Wang et al, 1999). The langurs live in habitats characterized by Karst topography. Groups are predominantly polygynous, and range from 5-13 individuals. Their society is typically characterized by female philoparty and male dispersal (Hu, 2007; Wu, 1983).

Previously, attacks on infants after male takeovers have been seen in the white-headed langur ( $T$. leucocephalus), a close phylogenetic relative living in similar habitat (Li, 2000; Zhao et al, 2011), but not in the François' langur. This behavior was considered to be infanticide, and a male reproductive strategy $(\mathrm{Li}, 2000$; Zhao et al, 2011). Here, we provide data from several months of observation, documenting three cases of

Received: 03 September 2012; Accepted: 05 November 2012 Foundation items: This work was supported by National Nature Science Foundation of China (31172122); Guangxi Nature Science Foundation (2012GXNSFAA053039)

* Corresponding author, E-mail: cmhuang@ioz.ac.cn 
attacks on adult females with infants by immigrant adult males in a free-ranging group of François' langurs. We suggest that these attacks were attempts at infanticide and thus targeted at the infant. Our main aim here is to explore possible causes of male attacks, and evaluate the validity of the sexual selection hypothesis to explain these data.

\section{STUDY SITES AND METHODS}

Nonggang Nature Reserve is located in the southwest of Guangxi province, China (E106 $42^{\prime}-107^{\circ} 4^{\prime}$, $\left.\mathrm{N} 22^{\circ \circ} 13^{\prime}-22^{\circ} 33^{\prime}\right)$, and comprises three areas: Nonggang (5426 ha), Longhu (1034 ha), and Longshan (3949 ha), which are separated by farmlands and villages. This reserve consists of limestone hills with elevations ranging from $300 \mathrm{~m}$ to $700 \mathrm{~m}$ above the sea level (Guangxi Forest Bureau, 1993) and vegetation is characterized as seasonal rainforest (Shu et al, 1988). Our field research was carried out in the northwestern portion of Nonggang, in the main study area of about 200 ha. The study group ranged near to our camp and had been semi-habituated to observers before data collection began. The size of the group varied from 12 individuals (4 adult males, 5 adult females, and 3 immatures) at the start of the study to 10 individuals by the end, owing to the disappearance of an adult female and her infant.

Between August 2003 and July 2004, we spent a mean of $10 \mathrm{~d}$ each month following the focal group. On each day, we observed the langurs via binoculars $(10 \times 60)$ at a distance of 10-200 m. During full-day follows, we began data collection at 06:00 and ended it when the subjects entered the sleeping site. We also collected behavior data during partial-day follows, which began when we first encountered the langurs. We collected no data in July 2004,due to widespread flooding, making follows almost impossible. We used instantaneous scan sampling in behavioral data collection, with $15 \mathrm{~min}$ intervals. A total of $739 \mathrm{~h}$ of behavioral data were collected.

Attacks were defined as the abrupt onset of an episode in an aggressive way, with or without body contact. Whenever an attack occurred, information on the attack, including time, identity of attacker and victim, the sequence, and the behavioral context, were recorded ad libitum (Altmann, 1974). Because observation was conducted from a considerable distance, or the event occurred at dusk, we could not identify all individuals, and accordingly only identified the age-sex classes involved. We estimated the age of infants based on the amount their pelage had changed from their natal coat color and body size.

\section{RESULTS}

\section{Dynamics of the study group}

The study group included 4 adult males at the start of this study, and group composition has changed during the study period (Table 1). Though François' langur society is typically characterized by female philoparty and male dispersal (Hu, 2007), an atypical instance of female dispersal may have occurred during our observation. An adult female with the youngest infant disappeared from the study group on 24 December, 2003 after attacks were directed towards her and her offspring (see below).

Table 1 Changes in group size and composition during study period

\begin{tabular}{cccc}
\hline Time & Group size & Group composition & Note* \\
\hline $2003.8 .13-2003.10 .2$ & 12 & 4 adult males, 5 adult females, 3 infants & \\
$2003.10 .4-2003.10 .9$ & 8 & 5 adult females, 3 infants & 4 adult males left group \\
$2003.10 .10-2003.11 .11$ & 12 & 4 adult males, 5 adult females, 3 infants & 4 adult males joined group \\
$2003.11 .25-2003.12 .13$ & 8 & 5 adult females, 3 infants & 4 adult males left group \\
$2003.12 .14-2003.12 .23$ & 12 & 4 adult males, 5 adult females, 3 infants & 4 adult males joined group \\
$2003.12 .24-2004.7 .25$ & 10 & 4 adult males, 4 adult females, 2 infants & an adult female with infant disappeared \\
\hline
\end{tabular}

*During the study period, we only found these 4 adult males in the main study area, so we inferred they were the same individuals.

\section{Attacks on adult females by adult males}

A total of three attacks on adult females by adult males were observed during the study period. All attacking events occurred after four adult males immigrated into the group (Table 1). Two victims were females with unweaned infants.

The first attack was observed at 18:35 on 20 December, 2003. The group was resting in a large tree near the sleeping site. An adult male approached the adult female with the youngest infant. The female began run away as soon as she became aware of the male. The male then chased the female. In this process, the infant was heard to scream loudly. Finally, the female escaped successfully from this attack and sat in a tree about $15 \mathrm{~m}$ away from the male. The female watched the male until he left. There was no body contact during this attack.

The second attack was observed on 21 December, 2003. At 18:25, the adult female with youngest infant first entered the sleeping cave on a cliff. At 18:30, an adult male moved quietly along the cliff to the sleeping cave. The adult female saw the approaching male and moved out quickly from the cave. Because the adult 
female with the infant could not rapidly move along the cliff, the adult male approached and slapped her head. The attacking male then tried to take the infant from its mother, but was unsuccessful. Finally, the female jumped from the cliff to a high tree nearby, escaping this attack. In the process of attack, the infant was heard to scream loudly. At 18:35, the adult male approached another adult female with oldest infant, who was resting on the cliff ledge. The adult female detected the approaching male early and moved away quickly. Because it was dark out, the male did not follow the adult female. Finally, the adult females slept in another cave, about $20 \mathrm{~m}$ from where the adult males slept.

The third attack was observed on 22 December, 2003. At 15:15, all members of the group rested on a big tree of the hilltop. The adult males were approximately 5 meters from the adult females and their infants. An adult male suddenly launched an attack towards the female with the youngest infant. Afterwards, he directs similar attacks at 15:20, 15:32, 15:40. In the process of attack, the attacking male persistently chased the female, but no body contact occurred. Finally, the female climbed down the tree and hid in the bush.

\section{DISCUSSION}

Infanticidal episodes usually occur soon after group takeovers or the death of the resident male (van Schaik \& Janson, 2000). Li (2000), for example, reported that three immature white-headed langurs (Trachypithecus leucocephalus) disappeared immediately after serious fighting between resident males and extra-group challengers. Zhao et al (2011) also reported that six infants disappeared after five group takeovers in whiteheaded langurs. Both suggested that infanticide may be the cause of the disappearance of the immature individuals. Although we did not witness a group takeover in this study, our observations may possibly be from the time just after the males drove the resident male away and took over the group. Sugiyama (1965) reported that in Hanuman langurs (Semnopithecus entellus), the attacking males repeatedly joined and left the group within several days after takeovers, consistent with the behaviors we observed among the François' langurs.

\section{References}

Agoramoorthy G, Rudran R. 1995. Infanticide by adult and subadult males in free-ranging red howler monkeys of Venezuela. Ethology, 99(1-2): 75-88.

Altmann J. 1974. Observational study of behavior: sampling methods. Behaviour, 49(3): 227-267.

Boggess J. 1979. Troop male membership changes and infant killing in langurs (Presbytis entellus). Folia Primatol, 32(1-2): 65-107.
All attacks on adult females with infants occurred after the 4 adult males immigrated into the study group. An adult female with her unweaned infant disappeared two days after the third set of attacks. Since we did not find a dead body, we presume that the female and her infant dispersed. As a close phylogenetic relative of the white-headed langur, we can reasonably infer that the attacks by the males were infanticide attempts and may have been the cause the adult female and her infant's dispersal. Studies of other primates have noted similar cases of dispersal to avoid infanticide by males (e.g., Cebus capucinus, Jack \& Fedigan, 2009; Colobus vellerosus, Teichroeb et al, 2009; Propithecus edwardsi, Morelli et al, 2009; T.leucocephalus, Zhao et al, 2011).

For the sexual selection hypothesis to be supported (Hrdy, 1979), the circumstances infanticide by males occurred requires the three conditions: (1) the infanticidal male is not related to the infant; (2) the mother goes into estrus more rapidly and conceives earlier after her infant is killed; and (3) the infanticidal male improves his chance of siring the subsequent infant. In this study, group composition changed during the study period, as 4 adult males left the group for 6-19 d at one time. Why the males left the group was unclear. Allfemales within the group appeared to be stable, and were moving, feeding, and resting as a cohesive group. Once the males joined the group, the adult females always kept a certain distance from them. The males also slept in a different cave or ledge on the cliff from the adult females and immatures at night (personal observation).

Collectively, the phenomena we observed during the course of this study suggest that the possibility the infants were related to the attacking males was low. However, this conclusion will still need to be confirmed by DNA analysis before we can draw any meaningful conclusions. Moreover, if the female with the youngest infant dispersed to avoid infanticide, the males would not have had mating access to her, therefore violating the sexual selection hypothesis. On the whole, these cases then do not completely verify the sexual selection hypothesis, but are neither inconsistent with it. Perhaps further observational studies can collect more data to clarify the relationship between infanticide and the sexual selection hypothesis.

Groves C. 2001. Primate Taxonomy. Washington, D C: Smithsonian Institute Press.

Guangxi Forest Bureau. 1993. Guangxi Nature Reserve. Beijing: Chinese Forestry Publishing House. (in Chinese)

Hrdy SB. 1979. Infanticide among animals: a review, classification, and examination of the implications for the reproductive strategies of female. Ethol Sociobiol, 1(1): 13-40. 
Hu G. 2007. Socioecology and Behavioral Flexibility of François' langur (Trachypithecus francoisi) in Mayanghe Nature Reserve, Southwest China . Ph.D. dissertation, Australian National University.

Jack KM, Fedigan LM. 2009. Female dispersal in a female-philopatric species, Cebus capucinus. Behaviour, 146(4): 471-497.

Li ZY. 2000. The Socioecology of White-headed langurs, Presbytis leucocephalus, and Its Implications for Their Conservation . Ph.D. dissertation, University of Ednbergh.

Morelli TL, King SJ, Pochron ST, Wright PC. 2009. The rules of disengagement: takeovers, infanticide, and dispersal in a rainforest lemur, Propithecus edwardsi. Behaviour, 146(4): 499-523.

Newton PN, Dunbar RIM. 1994. Colobine monkey society // Davies AG, Oates JF. Colobine Monkey: Their Ecology, Behaviour and Evolution. Cambridge: Cambridge University Press, 311-346.

Shu ZM, Zhao TL, Huang QC. 1988. Vegetation survey in Nonggang Nature Reserve. Guangxi Botany, 1(Suppl): 185-214. (in Chinese)

Sommer V. 2000. The holy wars about infanticide. Which side are you on? And why? // van Schaik CP, Janson CH. Infanticide by Males and Its Implication. Cambridge: Cambridge University Press, 9-26.
Steenbeek R. 2000. Infanticide by male and female choice in wild Thomas's langurs // van Schaik CP, Janson CH. Infanticide by Males and Its Implication. Cambridge: Cambridge University Press, 153-177.

Sugiyama Y. 1965. On the social change of hanuman langurs (Presbytis entellus) in their natural condition. Primates, 6(3-4): 381-418.

Sussman RW, Cheverud JM, Bartlett TQ. 1995. Infant killing as an evolutionary strategy: Reality or myth? Evol Anthrop, 3: 149-151.

Teichroeb JA, Wikberg EC, Sicotte P. 2009. Female dispersal patterns in six groups of ursine colobus (Colobus vellerosus): infanticide avoidance is important. Behaviour, 146(4): 551-582.

Van Schaik CP, Janson CH. 2000. Infanticide by Males and Its Implication. Cambridge: Cambridge University Press.

Wang YX, Jang XL, Feng Q. 1999. Taxonomy, status and conservation of leaf monkeys in China. Chn Zool Res, 20(4): 306-315. (in Chinese)

Wu MC. 1983. On the distribution and number estimate of primates in Guangxi Province. Acta Theriol Sin, 3: 16. (in Chinese)

Zhao Q, Borries C, Pan WS. 2011. Male takeover, infanticide, and female countertactics in white-headed leaf monkeys (Trachypithecus leucocephalus). Behav Ecol Sociobiol, 65(8): 1535-1547. 